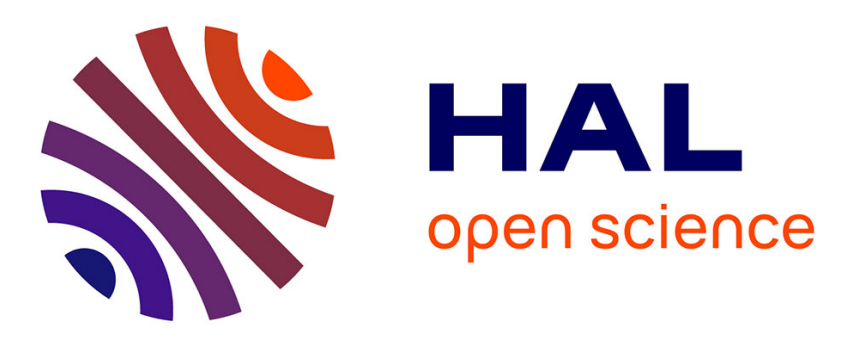

\title{
An Embedded Deep Brain Stimulator for Biphasic Chronic Experiments in Freely Moving Rodents
}

Florian Kolbl, Gilles N'Kaoua, Frederic Naudet, Florent Berthier, Emilie Faggiani, Sylvie Renaud, Abdelhamid Benazzouz, Noelle Lewis

\section{- To cite this version:}

Florian Kolbl, Gilles N'Kaoua, Frederic Naudet, Florent Berthier, Emilie Faggiani, et al.. An Embedded Deep Brain Stimulator for Biphasic Chronic Experiments in Freely Moving Rodents. IEEE Transactions on Biomedical Circuits and Systems, 2016, 10 (1), pp.72-84. 10.1109/TBCAS.2014.2368788 . hal-01347597

\section{HAL Id: hal-01347597 \\ https://hal.science/hal-01347597}

Submitted on 21 Jul 2016

HAL is a multi-disciplinary open access archive for the deposit and dissemination of scientific research documents, whether they are published or not. The documents may come from teaching and research institutions in France or abroad, or from public or private research centers.
L'archive ouverte pluridisciplinaire HAL, est destinée au dépôt et à la diffusion de documents scientifiques de niveau recherche, publiés ou non, émanant des établissements d'enseignement et de recherche français ou étrangers, des laboratoires publics ou privés. 


\title{
An Embedded Deep Brain Stimulator for Biphasic Chronic Experiments in Freely Moving Rodents
}

\author{
F. Kölbl, Student Member, IEEE, G. N'Kaoua, F. Naudet, F. Berthier, E. Faggiani, \\ S. Renaud, Member, IEEE, A. Benazzouz, and N. Lewis, Member, IEEE
}

\begin{abstract}
This paper describes a Deep Brain Stimulation device, portable, for chronic experiments on rodents in the context of Parkinson's disease. Our goal is to equip the animal with a device that mimics the human therapeutic conditions. It implies to respect a set of properties such as bilateral current-mode and charge-balanced stimulation, as well as programmability, low power consumption and re-usability to finally reach a suitable weight for long-term experiments. After the analysis of the solutions found in the literature, the full design of the device is explained. First, the stimulation front-end circuit driven by a processor unit, then the choice of supply sources which is a critical point for the weight and life-time of our system. Our low cost system has been realized using commercial discrete components and the overall power consumption was minimized. We achieved 6 days of maximal current stimulation with the chosen battery for a weight of $13.8 \mathrm{~g}$. Finally, the device was carried out in vivo on rats during a 3 weeks experiment as the used implantation technique allows battery changing. This experiment also permits to emphasize the mechanical aspects including the packaging and electrodes holding.
\end{abstract}

Index Terms-Biomedical engineering, Implants, Electrode driver, Deep Brain Stimulation, Low power.

\section{ISSUES ON DEEP BRAIN STIMULATION DEVICES FOR EXPERIMENTATION ON ANIMAL MODELS}

For over 20 years, effects of electrical stimulation of deep brain structures on motor symptoms of neuro-degenerative diseases have been of interest [1]-[4]. Deep brain stimulation $(D B S)$ involves sending electrical pulses at a given frequency in specific nuclei of basal ganglia. For Parkinson's disease, the first attempt of DBS treatment was applied in the Ventral Intermediate Nucleus [1], which stopped rest tremor but without beneficial effects on akinesia and rigidity. Henceforth, study on stimulation of other structures in animal models of the disease were conducted, showing that high frequency stimulation (HFS) of the subthalamic nucleus (STN) alleviated all the cardinal motor symptoms of Parkinson's $(P D)$ disease induced by MPTP in nonhuman primate model of the disease [5]. Based on this study, STN HFS was successfully applied to parkinsonian patients with advanced severe motor symptoms [2]. The electrodes of DBS, which are connected to a stimulator, are implanted chronically and continuous HFS of

F. Kölbl, G. N'Kaoua, S. Renaud and N. Lewis are with the Department of Bioelectronic in Laboratory IMS-CNRS UMR 5218, University of Bordeaux, e-mail: florian.kolbl@ims-bordeaux.fr.

F. Berthier is with CEA-Leti, Grenoble, France, e-mail florent.berthier@cea.fr.

F. Naudet, E. Faggiani and A. Benazzouz are with the Laboratory IMN, UMR 5293 CNRS, University of bordeaux, e-mail: abdelhamid.benazzouz@ubordeaux2.fr

Manuscript received March 21, 2014 the STN induces dramatic improvement of the cardinal motor symptoms, such as tremor, akinesia and rigidity [6]. However, even if the beneficial effect of DBS on PD symptoms is well established, the underlying mechanism is still under debate [7]. This knowledge should lead to improve DBS therapy and devices, as well as the application of the approach to other neurological and psychiatric disorders.

Brain disorders can be modelled in laboratory animals, in order to develop pathophysiological states associated with behavioural outcomes. Animal models can be used to understand the functional mechanisms of DBS and also to develop new applications to brain diseases resistant to drug treatments. Nevertheless, except for non-human primates, the human DBS commercial implants cannot be used in rodents because of their large size. Thus, it is mandatory to develop specific embedded stimulators that mimic therapeutic action provided in human patients and adapted to small animals.

In the present paper we propose a new DBS dedicated stimulator, adapted for chronic experiments on rodent models and that mimics the conditions of DBS human therapy: bilateral, current-controlled biphasic stimulation. Besides this objective, the device to be designed should be highly configurable and tunable by the neurophysiologists for further analysis. In terms of embedded system design, the different materials composing the stimulator should be individually and globally optimized: electrodes for accurate STN targeting, adapted stimulation waveforms, stimulation circuitry for low power consumption and high battery capacity [8].

The rest of the paper is organized as follows. In section II, experimental constraints on the stimulator are summed up and existing setups for rodent DBS are compared. Thereafter, the complete system design is developed. The stimulation frontend circuit and its control and supply parts are described in section III. In Section IV, an important point is discussed: the minimization of the power consumption and the selection of the energy source adapted to the constraints of the chronic experiments. Our system has not only satisfactory electrical characteristics, but it has also been tested in vivo. Thus the mechanical aspects of the system, the packaging, the holding of the electrodes are detailed in section $\mathrm{V}$, where results of implantation are also described. Finally, we discuss our results regarding the literature and conclude in section VI.

\section{State OF The ART OF EMBEDded DBS STIMUlators FOR RODENTS}

Before reviewing and comparing the existing solutions, let us consider the important properties imposed to DBS devices, 


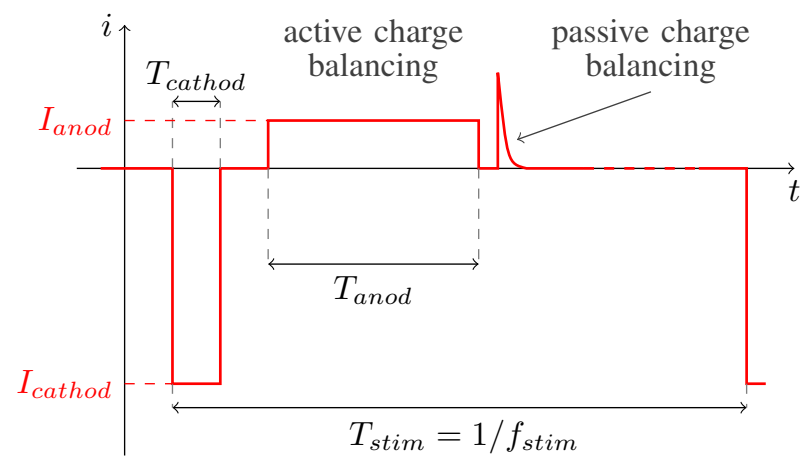

Fig. 1. Typical waveform of DBS current stimulation with active and/or passive charge balancing

according to the objectives previously announced: apply to the rodent the therapeutic conditions used for humans and be able to perform chronic stimulation on a freely moving animal.

\section{A. Stimulator properties and corresponding design constraints}

1) Tissue safety: Stimulation waveforms have to respect electro-neutrality of living tissue; therefore charge balanced stimulation protocols must be used [9]. Unbalanced waveforms for DBS can result in lesions around electrodes as related in [10]. As the electrical charge is the integral of current over time, DBS is often performed by constant current shaped pulses, with a total null area as detailed below.

Typical DBS current waveform is depicted in Fig. 1. A first negative current impulse, called cathodic pulse, is responsible for electrical stimulation of cells surrounding electrode contacts. Usually, the cathodic pulse duration $T_{\text {cathod }}$ for DBS is set to $60 \mu \mathrm{s}$ [11], in the range of targeted cell chronaxy [12]; to reach therapeutic effect, the cathodic current $I_{\text {cathod }}$ is increased until tremors stop. Pulse duration can ultimately be increased if more charges are needed to obtain the desired effect.

In order to have a charge-balanced waveform, two different techniques can be used or combined:

- Active charge compensation: a positive or anodic current pulse is delivered to the electrode. In order not to hyperpolarize neurons targeted by stimulation [9], the anodic current $I_{\text {anod }}$ is lower than the cathodic current. Anodic time duration $T_{\text {anod }}$ is then chosen to have a global charge over a stimulation period equal to zero and an interpulse delay is often added to prevent from cells hyperpolarization as explained in [9].

- Passive charge compensation: electrode is discharged through a resistor. This technique is the most efficient to ensure tissue safety, however the resulting current peak value is not under control and high current value can hyperpolarize targeted neurons [9].

Therefore, the design constraints related to tissue safety are to generate bidirectional currents under a wide range of voltage compliance, due to the variability and evolution of stimulated impedance
2) Bilateral stimulation: Chemical induced parkinsonism [13]-[16] can be either unilateral or bilateral. However, for DBS mechanism studies, behavioral evaluation has to be performed on groups of animals. In order not to induce dissymmetry in movement, bilateral Parkinsonism is used in majority of studies. This implies to implant two electrodes, one for each right and left subthalamic nucleus, and provide an adapted stimulation.

On rodents, the distance between the right and left subthalamic nuclei is relatively small $(5 \mathrm{~mm}$ according to the rat brain atlas of Paxinos and Watson, 1986), and electrodes have to be implanted over a short operative time to limit the impact of anesthesia on the animal. A simple solution to face this problem is to design mechanically coupled electrodes. Hence, the stimulation can be made separately, with a two-channel system, or combined, with a one-channel system delivering twice the current needed on a single electrode.

The bilateral stimulation results then in design constraints on the electrodes and on the level of the delivered current. In this paper we discuss the required stimulation current as the sum of the currents for both hemispheres.

3) Programmability: The DBS waveform is periodic and its frequency $f_{\text {stim }}$ is an important parameter. Frequencies less than $10 \mathrm{~Hz}$ are known to increase motor symptoms of $\mathrm{PD}$, whereas frequencies over $50 \mathrm{~Hz}$ tend to decrease them; furthermore, the current threshold decreases as the frequency increases [11]. A generally accepted compromise to lower current levels is to set up stimulation frequency to $130 \mathrm{~Hz}$, however this parameter can be changed if unsatisfactory physiological responses are observed. All stimulation parameters (frequency, amplitude and pulse duration, as shown in Fig. 1) should be tuned to obtain motor symptom reduction, as observed in a freely moving animals.

Moreover, these parameters can change after the implantation of electrodes and have then to be re-adjusted easily; some protocols even impose to stop stimulation, as for example MRI imaging. As we intend to address long-term stimulation, the design of the system must allow the easy tuning of the waveform parameters and the storage of a given experimental configuration.

4) Freely moving animal: This point is crucial in order to correctly evaluate therapeutic effect of DBS on rodent, especially complex motor activity and depression-like behavior [17].

Motor activity evaluation can be done using various tests. The most commonly used is the evaluation of locomotor activity in the open-field [18]-[20]. This test supposes an ease of access in the space; other motor tests have been developed to evaluate rigidity and catalepsy, which are two symptoms of PD, like for example the bar-test [21]. Parkinsonian non-motor disorders can also be quantified by the elevated plus maze [22], where the rodent has access to closed or open arms of the maze (anxiety-like behaviour), or sucrose preference [23], for which the animal is placed in the presence of two bottles to drink (depression-like behaviour). All these behavioural tests require the use of special equipments and the free motion of the animal in various areas without discomfort of being linked to an electrical device. 
The resulting constraint for the stimulator is to be embedded on the rodents. As a consequence the volume and weight have to be managed. The volume is linked to the system placement in or on the body. The weight has to be bearable for the animal. We adopted an upper weight limit considering the physiology of the animal model: this limit corresponds to $5 \%$ of the average weight (around $400 \mathrm{~g}$ ) of a male Sprague Dawley rat, the commonly used specie for physiological experiments. The entire system (electronics, battery and cases) has to be less than $20 \mathrm{~g}$ to limit impact on animal.

5) Lifetime stimulation: The embedded supply source has to provide enough energy for long term experimentation, either being changed or recharged. As a consequence, the overall power consumption has to be as small as possible without interfering with needs inherent with tissue safety. This condition has to be taken into account at all steps of stimulator design, from the front-end circuit topology to the global system powering strategy, including the choice of embedded battery.

6) Re-usability and cost: DBS studies on action mechanisms or side effect evaluations are based on chronic population experiments. The cost of the stimulation system has a big impact on the feasibility of experiments. The ideal stimulator for rodent experimental setup can be re-used for several experiments. In this case the battery has to be changed easily without excessive additional cost.

The need for cost effectiveness also has a repercussion on the adopted technology. Most of the available stimulators are designed on chips, although custom Application Specific Integrated Design solutions can be costly. All integrated solutions also have the drawback of being less flexible than the ones using off-the-shelf components, making them less adaptive for therapy enhancement studies. However the use of discrete electronics impact is not in favour of the system miniaturization.

\section{B. Existing embedded stimulators for rodents}

First used methods for electrical stimulation on freely moving rodents were based on rotating wire placed over animal's cage [18]. For the time of stimulation the animal had a wire plugged over their skull. However this solution limits the number of behavioral testing to an area defined by cable length; exploration of outlying area can induce tensions on animal skull where the electrode is fixed to the skull.

Several embedded DBS systems have already been designed for rodents, trying to satisfy previously reported constraints. We propose to review these solutions, focusing on one important criterion: the location of the circuit in rodent body.

Two studies [24,25] have reported systems with an electronic part implanted in the abdominal area of rodents, connected to an electrode implanted in the brain. The major advantage is that the animal can move easily after surgery. Nevertheless this choice presents major risks consecutive to surgery, like infections, especially in the abdomen region. It is then mandatory to use biocompatible materials.

In both studies, stimulation parameters are programmed using RF links; in [25], communication is done using Reedswitches and the RF emitter is a tubular device containing the animal during the programming of stimulation. Of course, the animal movements are highly restricted and DBS action cannot be evaluated during programming. The battery is inside the animal body, implanted with the circuit, which requires additional surgery to change it, with additional infections risks. Moreover the use of RF link has a cost on global power consumption. In [24] no detail is given on tissue safety. Authors of [25] use charge balanced current waveforms. This first kind of DBS device is not adapted for experiments on rodents since it provides a high risk of side effects for a short time of action.

A second kind of embedded stimulators have been described in [16] and [26]. Both devices are wearable stimulators placed in vests. This solution solves two drawbacks of implanted devices: first, side effects of surgery are limited to electrode insertion and it is not necessary for electronics to be biocompatible as it is not in contact with tissues. Second, the battery is accessible on the back of the rodent and can be changed for long term experiments.

Nevertheless, such experiments are limited: animals also have to be placed in separated cages; even though, they can tear off their vest, and they risk severe brain damage if the electrodes are pulled out. The use of these wearable devices is in the end too risky for long term experimentation, even if both systems of [16] and [26] respect electrical conditions of tissues safety.

A third type of stimulators are detailed in [27] and [28]. These stimulators fixed to the skull whith dental cement while electrodes are implanted into the brain. The risk of infection is limited compared to the first category of stimulators. Moreover, the risk of breaking the device is small if its volume and weight are limited. In [27] the battery cannot be changed due to the chosen packaging. In [28], the entire stimulator device can be separated from the head allowing a simple battery change and the use MRI apparatus during the experiment. Nevertheless authors of [28] did not consider the standards [9] for safe electrical stimulation.

In conclusion, the latter stimulator category seems to be the most suitable for long term experiments. All presented stimulators [16,24]-[28] were designed for unilateral stimulation, a setup only suitable for 6-OHDA-induced hemi-parkinsonism. As neurodegenerative diseases are bilateral, we have chosen to develop a system which allows bilateral implantation of electrodes in the STN of both cerebral hemispheres. For bilateral stimulation only one stimulation channel is needed but the maximum current has to be doubled.

Our system is the first DBS device developed for chronic long-term experiments on populations of rodents, respecting all safety procedures as summarized previously. Hereafter we describe in detail the circuit design, architecture and sizing, as well as considerations on power optimization, battery selection, and the specificities of the package attached to the implanted electrodes.

\section{Front-End Stimulation CIRCUIT}

The front-end stimulation is the only part of the DBS device directly connected to electrodes. This circuit is in charge of 


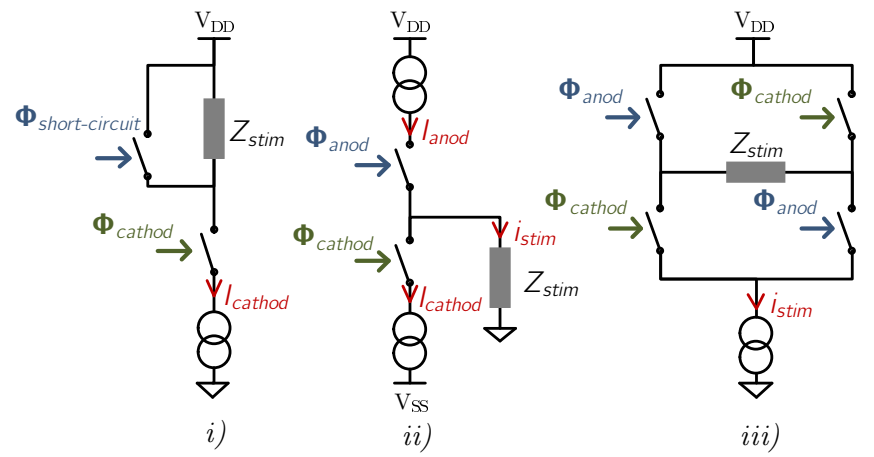

Fig. 2. Different circuits used for biphasic stimulation front-end. For structures $i$ ) and $\mathrm{iii}$ ), the ground signal is the lowest potential of the supply source, for structure ii) the ground signal is the middle point of the symmetrical supply.

delivering the adequate current to the tissue. It may work under a high output voltage considering the impedance loading while respecting charge balancing.

\section{A. Architectures for low-power electrical stimulation}

The generic front-end for electrical stimulation consists of a current source connected to an electrode using a combination of switches. As a unique current source can only provide a monopolar current, different architectures combining switches and sources have been developed to allow the injection of positive or negative current and thus ensure charge balancing. Three structures, presented in Fig. 2, are basically used in stimulation circuits.

Structure $i$ ) in Fig. 2 [29]-[31] is based on one current source and two switches. This topology can only provide biphasic stimulus with passive charge balancing. Such circuits are suitable for embedded systems because of their asymmetric power supply and the simplicity of driving requirements. Nevertheless passive charge balancing is not suitable for DBS where huge amounts of charges are delivered to the tissue: the peak current reached when the electrode is in short-circuit is too high for therapeutic conditions.

Active charge balancing requires a second current source as described in [29,32]-[38] and illustrated in Fig. 2 ii). Anodic and cathodic currents are generated by separate sources and two switches control the timing of stimulation pulses. The electrode is referenced to ground signal, as a consequence, power supply must be symmetrical. This architecture requires a more complex powering circuitry, able to reach the high bipolar voltage needed to drive the electrode. As the resulting biasing power is approximately twice as high as for the previous topology, this architecture is not suitable for low power embedded systems. This topology is also not ideally performing in terms of charge balancing. The use of two sources at the highest and lowest potentials makes a mandatory use of respectively $\mathrm{P}$ and $\mathrm{N}$ transistors. Therefore the current sources are not perfectly paired and charges resulting from balancing errors can accumulate at the bio-electronic interface. If matching calibration techniques can be applied [39], a third switch is often added in that topology to provide passive discharge to solve such problems.
A third architecture is often used in stimulation systems [40]-[49], providing active charge balancing with one current source and four switches as shown in Fig. 2 iii).The current polarity through the electrode is changed, using switches organized in an H-bridge. The supply voltage is then asymmetric. The use of only one current source allows both a reduction of the global power consumption and simplifying the charge balancing. Passive charge balancing can also be performed by breaking the symmetry of switch command or by adding a fifth switch in parallel with the stimulated load. Nevertheless, due to the floating stimulation load, this structure cannot be used with multi-channel electrodes that have a common current return path as in [50] for example; in such a configuration, asynchronous stimulation of different channels can cause short-circuits between electrodes and possibly cause damage by involuntary charge injection in the tissue. In this case the Fig. $2 \mathrm{ii}$ ) is the only solution to provide biphasic current stimulation. As DBS uses a pair of electrodes with individual current return path for each cerebral hemisphere, the topology described in Fig. 2 iii) is the most suitable for chronic embedded DBS systems.

Whatever the adopted topology, there is a risk of involuntary charge accumulation in the tissue, due to small leakage currents. To prevent from such a situation, a DC blocking capacitor must be placed in series with the electrode. In Fig. 2, $Z_{\text {stim }}$ is the combination of the electrode impedance and the DC blocking capacitor. The value of this additional capacitance is generally chosen so that the voltage drop is negligible compared to the voltage across the electrode in normal operation mode; nevertheless the global impedance $Z_{\text {stim }}$ has to be taken into account when determining the maximum output voltage at the highest current values, to choose the appropriate voltage supply.

To realize our embedded DBS system, we chose the Hbridge topology presented in Fig. $2 \mathrm{iii}$ ). The system, described in Fig. 3, uses two levels of supply voltage. A low voltage supply $V_{d d}$, from the batteries, is connected to the current source and control circuits. The H-bridge is supplied with the high level voltage $V_{H V}$ generated by a DC/DC converter.

$V_{d d}$ is fixed by the choice of battery technology, and can vary due to the state of charge. In order to deliver a constant waveform over time, the stimulus generator uses a supply voltage independent current source. The schematic of this source is explained in section III-B. Additional circuits for timing control and voltage-level conversion are described in section III-C.

\section{B. Supply-voltage-independent programmable current source}

We designed a current source (see Fig. 3 and Table I for parts' references) that can be controlled using a variable resistance and switched $\mathrm{ON}$ and $\mathrm{OFF}$ to limit the impact of biasing on the power consumption. In order to limit the consumption and the area with discrete components, current sources topologies using operational ampifiers were excluded; the adopted current generator is mainly based on a single transistor $T 2$. Transistors $T 3$ and $T 4$ are forming a current mirror to link the source output to the front-end stimulation. 


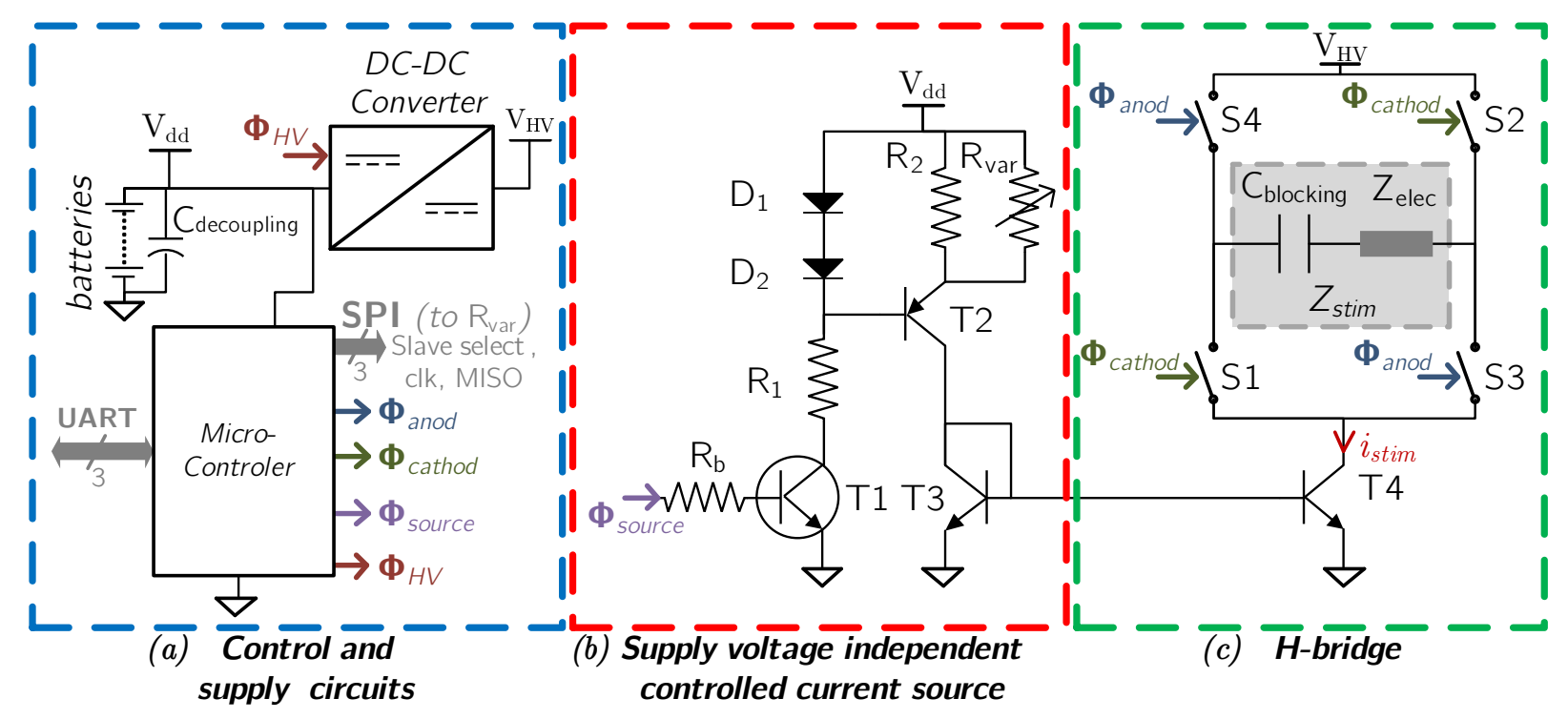

Fig. 3. Overall schematic of the developed DBS system. The circuit is divided in three parts. $(c)$ The stimulation current $\left(i_{s t i m}\right)$ is delivered to the load $\left(Z_{\text {stim }}\right)$ composed of the electrode $\left(Z_{\text {elec }}\right)$ and the blocking capacitor $\left(C_{\text {blocking }}\right)$, by a H-bridge topology (green rectangle). (b) The current value is fixed by a supply voltage independent current source (red rectangle). (a) Supply circuits and a micro-controller (blue rectangle) drive blocks $(c)$ and $(b)$.

TABLE I

LIST OF ACTIVE COMPONENTS USED IN THE STIMULATOR

\begin{tabular}{lcc}
\hline Part & Reference & Manufacturer \\
\hline$\mu C$ & MC9S08SH8 & Freescale \\
DC/DC Converter & LT3494 & Linear Technology \\
$D_{1}, D_{2}, T_{1}, R_{1}, R_{2}$ & PSSI2021-SAY & NXP \\
$T_{1}$ & BC847-BW & Phillips \\
$T_{3}, T_{4}$ & BCV61-C & Infineon \\
$S_{1}-S_{4}$ & MAX4623 & MAXIM \\
$R_{v a r}$ & MAX5484-ETE+ & MAXIM \\
\hline
\end{tabular}

In order to reach accurate copying, $T 3$ and $T 4$ are matched transistors included in the BCV61C part. The current source is formed by the combination of $D 1, D 2, T 2, R 2$ and $R_{v a r}$. To reach accurate values and reproducibility, $D 1, D 2, T 2$ and $R 2$ can be found in package using a PSSI2021SAY. Assuming that emitter and collector currents of $T 2$ are equal, the biasing current is:

$$
i_{c T 2}=\frac{2 V_{D \text { on }}-V_{\text {be on }}}{R 2 / / R_{\text {var }}}
$$

where $V_{D \text { on }}, V_{\text {be on }}$ are voltages across the diodes and the BJT base-emitter junction. Both $V_{D}$ on and $V_{\text {be on }}$ can be considered as constant values if a sufficient biasing current is provided. If necessary, this condition can be reached by lowering the value of $R 1$. Transistor $T 1$ is used as an ON/OFF switch, so that minimum voltage across $R 1$ is determined by:

$$
V_{R 1 \min }<V_{d d}-2 V_{D \text { on }}-V_{\text {ce sat } T 1}
$$

Contributions of $R 2$ and $R_{v a r}$ can be separated. $R 2$ ensures a fixed minimum current (in our case $i_{R 2}=15 \mu A$ ) and $R_{v a r}$, when decreasing, increases stimulation current. For $R_{v a r}$, we used a digitally programmable resistance (MAXIM MAX5484). The resistance variation is then linear, coded on a 10 bits value; the expression of the global stimulation current is then:

$$
i_{\text {stim }}=i_{R 2}+\frac{\left(2 V_{D \text { on }}-V_{\text {be on }}\right)}{R_{\min }+D \cdot R_{q}}
$$

where $D$ is the 10 bits value coding the resistance $(D \in$ $\llbracket 0,1023 \rrbracket), R_{q}$ is the quantum of resistance $(R q=50 \Omega)$ and $\operatorname{Rmin}(\operatorname{Rmin}=110 \Omega)$ is the minimum resistance of $R_{v a r}$. From this equation, one can observe that the variation law of current is a hyperbolic function of $R_{v a r}$ code as illustrated in the figure 4(a). Such variations have already been used for neural electrical stimulation [26] and seem adapted to $D B S$, where higher values of current are not often used unless there is electrode misplacement during surgery [11].

Power on the H-bridge depends directly on electrode impedance $Z_{\text {stim }}$ and $i_{\text {stim }}$; the power consumption of the programmable current source is approximated by:

$$
P_{\text {source }} \approx V_{d d}\left(\frac{V_{d d}-2 V_{D \text { on }}-V_{\text {ce sat } T 1}}{R 1}+i_{\text {stim }}\right)
$$

The first term is due to the current source biasing and can be reduced by increasing $R 1$ with respect to equation 2 . The second term is directly linked to the required stimulation current. The supply voltage $V_{d d}$ could be decreased, depending on the battery technology choice which will be detailed in section IV.

\section{Control and supply circuits}

The control circuit generates the switch commands for cathodic and anodic pulses $\Phi_{\text {cathod }}$ and $\Phi_{\text {anod }}$ by driving analog switches realized with a MAX4623, and sends the values of the required current levels through the command of the variable resistance using a Serial Peripheral Interface (SPI) link. This circuit also controls the current source bias voltage $\Phi_{\text {source }}$ and the command of the high-voltage power 


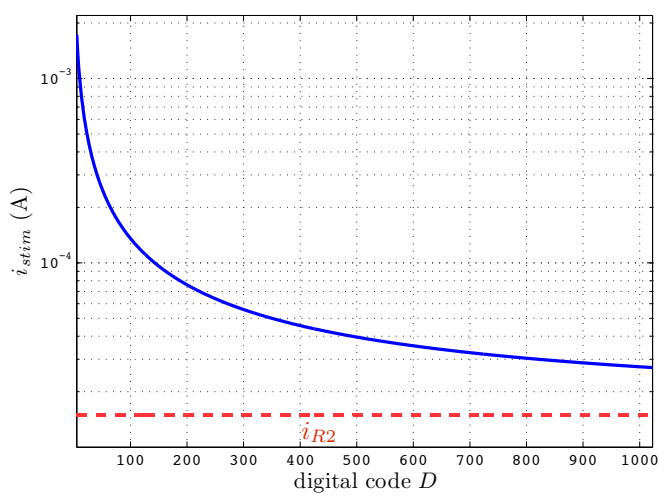

(a)

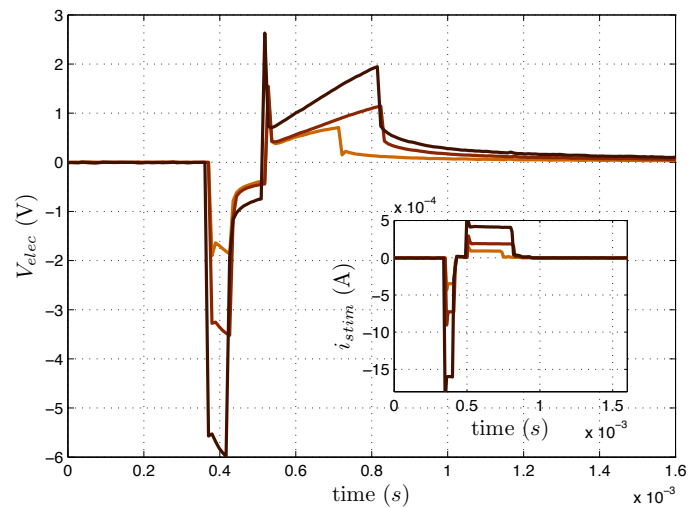

(b)
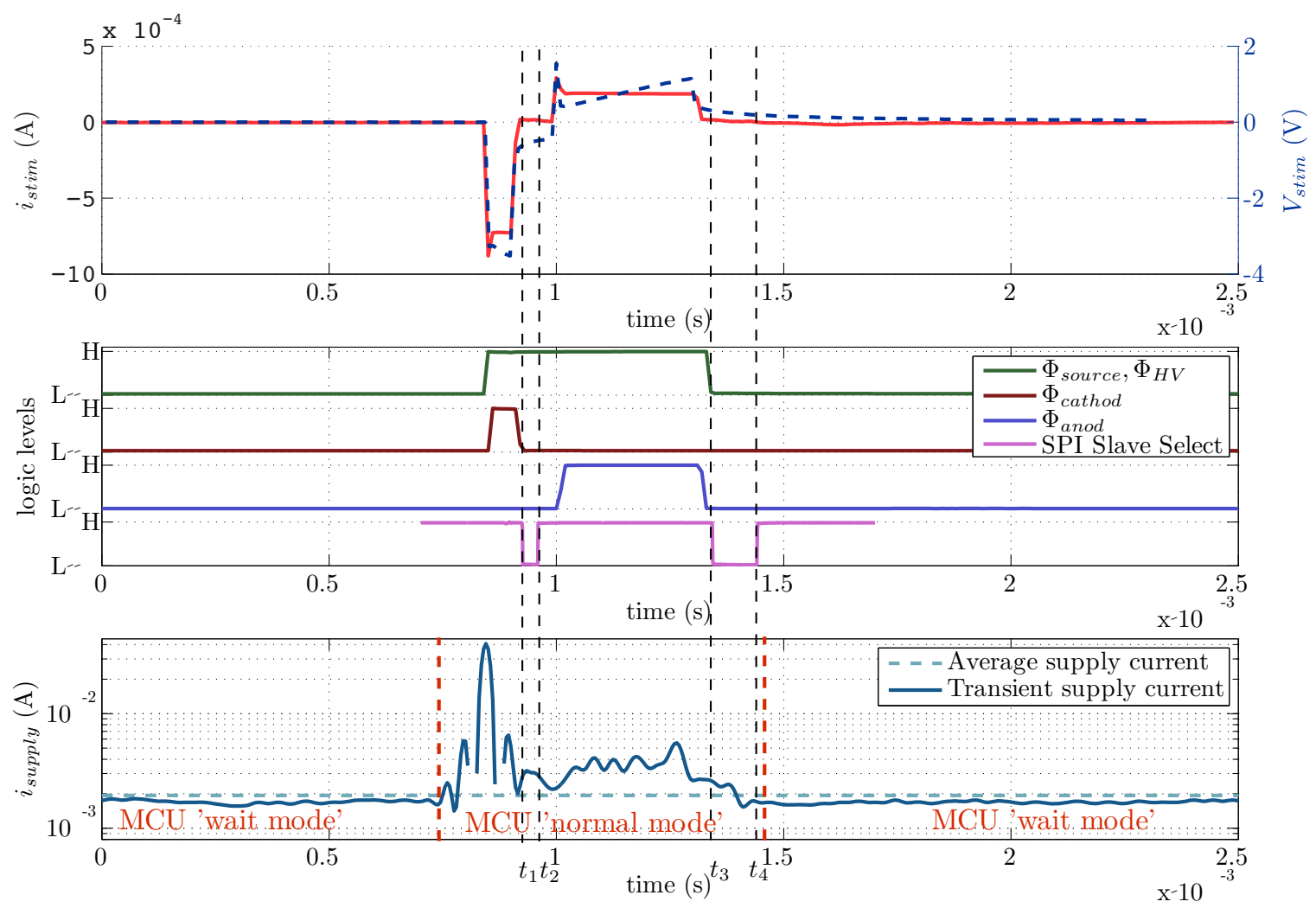

(c)

Fig. 4. (a) Graphical representation of the stimulation current $i_{\text {stim }}$ as a function of the digital code of the variable resistance (b) Electrode response for biphasic stimluation of $I_{\text {cathod }}=400,800$ or $1600 \mu \mathrm{A}$ and $60 \mu \mathrm{s}$ pulse (c) Recorded chronogram of a typical stimulus $(60 \mu \mathrm{s}$ of $750 \mu \mathrm{A}$ cathodic current, charge balanced with a $250 \mu \mathrm{A}$ current pulse and $60 \mu \mathrm{s}$ of inter-pulse delay with a frequency of $130 \mathrm{~Hz}$ ), corresponding logic commands and supply current. The average consumed current is reesented by a dashed line $(1.9 \mathrm{~mA})$ for the used stimulation pattern

supply $\Phi_{H V}$. A typical stimulation pattern is described in Fig. 4(c).

Parameters necessary to define a standard current stimulus as in Fig. 4(c) are: current sign and value, as well as timing of the cathodic and anodic phases.

Current sign management is done by generating cathodic and anodic signals in the right orders. The programming of a current value is performed with a SPI link, driving the variable resistance described in previous section (a 10 bits variable digital resistance with 1 code volatile memory register). As currents are coded on 10-bits values, two bytes are sent by the $M C U$ to generate each current value. However, for a given SPI baud-rate, this procedure is limited by the interval between two current pulses. In typical case, the inter-pulse timing, see Fig. 1, for $D B S$ is $60 \mu s$.

The most challenging section is the switching between cathodic and anodic values. Limiting the SPI baud-rate allows to minimize the MCU frequency, and thus the power as explained in the next section. The anodic code is stored in the resistance's non-volatile register when initializing a 
new waveform, and is no longer transmitted; immediately after, the cathodic code is transmitted to the tap register to generate the first cathodic pulse. During the inter-pulse delay of each stimulation period, the non-volatile-register is copied in the resistance's tap register using a one byte communication (between markers $t_{1}$ and $t_{2}$ on Fig. 4(c)) to generate the anodic current. After the anodic phase, i.e. at the end of the stimulation waveform, the cathodic code is re-sent using two bytes to the tap register (between markers $t_{3}$ and $t_{4}$ ), configuring the current source for the next stimulation period. A timing difference $\left(t_{2}-t_{1}<t_{4}-t_{3}\right)$ can be observed on the logic output of the SPI Slave Select. With this strategy and a limited baud-rate of $147.5 \mathrm{kbit} \cdot \mathrm{s}^{-1}$, the minimal inter-pulse delay is:

$$
T_{\text {inter-pulse }}=\frac{N_{\text {bits }}}{B R} \geq \frac{8}{147.510^{3}}=54.24 \mu \mathrm{s}
$$

With our current source and time resolution $(500 \mathrm{~ns})$, charge balancing has a limited accuracy and a maximal equivalent DC current error measured at $520 \mathrm{nA}$ with a picoammeter/voltage source Keithley 6487. In order to decrease this unbalance, we implemented once every 256 periods (approximatively $2 s$ ) a passive discharge, by closing all switches and disabling the current source $\left(\Phi_{\text {anod }}=\Phi_{\text {cathod }}={ }^{\prime} 1^{\prime}, \Phi_{\text {source }}={ }^{\prime} 0^{\prime}\right)$; the maximal error is then reduced to $72 n A$; the additional DC blocking capacitor prevents from any residual charge on the tissue.

As illustrated in Fig. 3, the high voltage level necessary to provide current stimulation is generated from the embedded battery through a DC/DC switched mode power supply. The used topology is a Boost-Converter (Linear Technology LT3494) that levels up the voltage. The voltage across electrodes was measured for different levels of currents [51]. As voltage depends on both current value and pulse width, a measurement was conducted on saline solution with maximum values (i.e. $2 \mathrm{~mA}$ and $500 \mu \mathrm{s}$ ) and the maximum measured voltage was near $8 \mathrm{~V}$, a set of electrode reponse voltages are presented in figure 4(b). The boost converter has to provide sufficient voltage for the electrode and for the voltage drop of DC blocking capacitor, switches and the current source. Moreover, the electrode impedance is known to increase after surgical implantation [52]. To ensure stimulation in any situation, a high voltage supply of $17.6 \mathrm{~V}$ was used in the front end. This level can be adapted by changing external components of the used Boost-Converter.

\section{CONSIDERATIONS ON SYSTEM SUPPLYING}

As often for embedded medical applications, the most challenging constraints for our chronic stimulator are the required power and energy. The power is imposed by the load, the system requirements and the circuit topology. We present in IV-A our strategy to minimize the power consumption. The energy challenge is related to the need for chronic stimulation, with minimal disturbance for the animal carrying the power source. In IV-B we will discuss the available battery technologies, and propose a suitable choice in our context.

\section{A. Power management}

In order to be integrated on animals skull, the volume and weight of the overall system have to be minimized. As the most prominent part of miniaturized systems are dedicated to power sources, the overall power of the system has to be optimized without influencing developed functionality. The power consumed by the system presented in Fig. 3 is given by:

$$
P_{\text {stimulator }}=P_{\mu C}+P_{\text {source }}+P_{H-\text { bridge }}+P_{\text {boost }}
$$

where $P_{\mu C}$ is the power of the MCU (Fig. 3 (a)), $P_{\text {source }}$ is the power consumed by the controlled current source (Fig. 3 (a)), $P_{H \text {-bridge }}$ is the power consumed in the H-bridge (Fig. 3 (c)) and $P_{\text {boost }}$ is the power consumed by the step-up DC/DC converter (Fig. 3 (a)).

We saw in a previous section that the current source power consumption can be reduced by limiting the diode current of $D 1, D 2$ (see Fig. 3). Moreover this current source can be turned off when not used by blocking transistor $T 1$ (see Fig. 3). $P_{H \text {-bridge }}$ is approximated to the load power consumption as the switches equivalent resistance is negligible compared to the electrode impedance.

To evaluate and optimize the remaining terms, $P_{\mu C}$ and $P_{b o o s t}$, we have to take into account both the mode of operation and the MCU frequency. Typical $D B S$ stimulus waveform, as shown in Fig. 1, consists of short current pulses regarding the stimulation period. For example, consider a frequency of $130 \mathrm{~Hz}$, a cathodic pulse of $60 \mu \mathrm{s}$, an inter-pulse of $60 \mu \mathrm{s}$ and an anodic pulse of $600 \mu \mathrm{s}$ (ie. a cathodic current 10 times higher than the anodic current), the percentage of the period $1 / f_{\text {stim }}$ during which no stimulation is applied to electrode is:

$$
1-f_{\text {stim }} \cdot\left(T_{\text {anodic }}+T_{\text {cathodic }}+T_{\text {inter-pulse }}\right) \approx 0.906
$$

This simple consideration implies that the stimulation hardware can be turned off most of the time (typically, more than $90 \%$ of time).

$P_{b o o s t}$ is inversely proportional to the efficiency of the Boost converter, and related to the output current. This current cannot be controlled since it is directly the stimulation current, but can be smoothed by adding decoupling capacitors of high values at the step-up output. Nevertheless, the boost circuit input power is also determined by its quiescent current. We choose a boost IC (LT3494) that can be turned in a shutdown mode, changing the quiescent current from $65 \mu A$ to $1 \mu A$. $\Phi_{H V}$ (see Fig. 3) controls the boost circuit commutation between the active and power saving mode, as illustrated in Fig. 4(c).

The most power consuming part of the system is the MCU. $P_{\mu C}$ can be separated in a static part and a frequencydependent term:

$$
P_{\mu C}=P_{\text {stat }}+P_{C P U}=P_{\text {stat }}+k \cdot f_{c l k} V_{d d}^{2}
$$

where $k$ is a constant in Farad, that depends on the processor technology and sizing. The static power of the MCU (Freescale MC9SO8SH8) is determined by its operating mode. In 'normal' mode, the static power is maximal and all peripherals are turned on. In 'Wait' mode, the static power is 
decreased and the $C P U$ goes to a standby mode from which recovery is fast. One 'Stop' mode can be used to limit even more power consumption but its recovery time is incompatible with the need for fast events described on Fig. 4(c). The clock frequency used for the $C P U$ unit of the MCU has a proportional impact on power consumption. This power saving strategy has been applied on the developed system as shown in chronogram of Fig. 4(c).

The current source and step-up are turned on before cathodic command is applied to the H-bridge (see Fig. 4(c)). This activation corresponds to the first action of the MCU, changing from 'Wait' to 'Normal' mode. After the anodic pulse, the MCU is set under 'Wait' mode again, just after shutting down the current source and the DC/DC converter. With this strategy, the supply current value is limited when no stimulation current is applied. Nevertheless $f_{c l k}$ has to be taken into account when the MCU is in Normal mode, ie when a stimulus is applied or when the stimulation system is receiving stimulation parameters. All these events are processed using hardware interrupts. The associated sub-routines have to be executed in time periods that are negligible compared to stimulation patterns, even configured for the shorter pulse duration $(60 \mu \mathrm{s})$. We chose $f_{c l k}=2 M H z$, which is the lowest frequency ensuring the calculated SPI baud rate (see eq. 5); this value is much higher than traditionally adopted clock frequencies [24,25] (under the $M H z$ ), however, thanks to this power management strategy, the average current consumption is only $1.9 \mathrm{~mA}$ (see Fig 4c), a level comptible with battery supplied systems. The resulting transient supply current was measured as presented in Fig. 4(c). The peak current around $40 \mathrm{~mA}$ on a short period (less than $10 \mu \mathrm{s}$ ). The transient supply remains stable during the stimulation period except when the MCU is experiencing recovery time in the Wait mode.

\section{B. Choice of supply sources}

We expected to find a supply source able to deliver a current profile as in Fig. 4(c), and have the maximal energy with a system weight limit of $22.5 \mathrm{~g}$ as specified in section II. As our current source is independent of the supply voltage, the low voltage supply $V_{d d}$ can be chosen between $2.9 \mathrm{~V}$ and $5.5 \mathrm{~V}$.

Human oriented Implanted Medical Devices (IMD) batteries have been of interest since the first implantation of pacemakers about 50 years ago [53]. Supply sources occupy $25-60 \%$ of their volume [54], and technology improvements have enhanced patient's quality of life, by limiting surgery. Different technologies are used for human oriented $I M D$, depending on the therapeutic target and associated power requirement [53]-[56], as summarized in Table II. Lithium technology is largely dominant for these applications. These technologies are potentially interesting for our stimulator; however, the weight of batteries used for human IMD largely exceeds $20 \mathrm{~g}$. And regarding overall performances, weight and size reduction affects the total embedded energy but also reduces available power, as the surface of electrode plates is smaller.

We conducted a dedicated study to find the optimal power source, respecting our cost-effectiveness needs for chronic population implantation. In order to evaluate most adapted
TABLE II

TYPICAL BATTERY TECHNOLOGIES USED FOR DIFFERENT TYPES OF IMD CORRESPONDING TO DIFFERENT POWER REQUIREMENTS

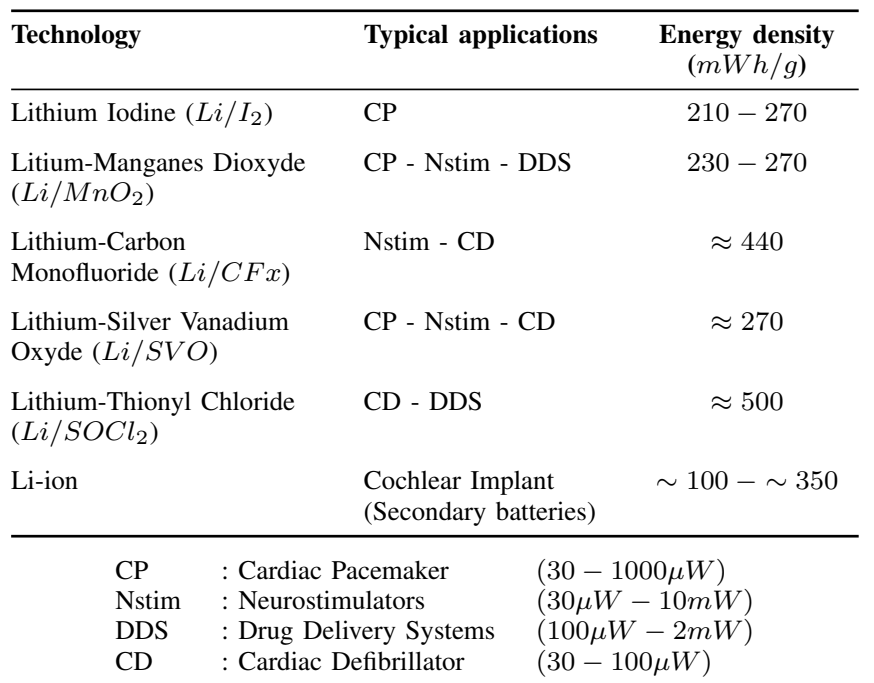

technologies for this system, we compared commercially accessible batteries of less than $20 \mathrm{~g}$. Based on available datasheets, maximal constant current was extracted and related to cell voltage to compute the available power; the energy was computed using the capacity and the cell voltage; both parameters can then be normalized with the weight of the element. Results are shown in terms of energy versus power and energy density versus power density (see Fig. 5). This study only takes into account the average nominal power as a first criterion. To support the peak power observed in Fig. 4(c), a secondary source acting like a decoupling capacitor will be chosen, as explained later in the section.

We observe from Fig. 5 that not only lithium batteries are potential candidates for our application. Zinc technologies, except for $\mathrm{Zn} / \mathrm{Ag}_{2} \mathrm{O}$, tend to have available energy higher than lithium technologies. The $\mathrm{NiMH}, \mathrm{Zn} / \mathrm{MnO}_{2}$ and $\mathrm{LiPo}$ batteries tend to deliver more power than other technologies. The analysis of the energy density versus power density in Fig. 5(b) results in three groups of candidates:

- The first one is composed of $\mathrm{NiMH}, \mathrm{Li} / \mathrm{V}_{2} \mathrm{O}_{5}$, $\mathrm{LiPo}$ and $\mathrm{Zn} / \mathrm{Ag}_{2} \mathrm{O}$. It is characterized by a reduced energy density compared to others technologies $(\leq 102 m W h / g)$. Such batteries cannot supply the stimulator more than approximately 16 hours per gram, whereas their power density could be adapted (except for $\mathrm{Zn} / \mathrm{Ag}_{2} \mathrm{O}$ ).

- The second group is composed of $L i / C F x$ and the majority of $\mathrm{Li} / \mathrm{MnO}_{2}$ batteries; these batteries show higher energy density but have a reduced power density that makes them not suitable for the application.

- The last group is composed of Zinc/Air, $\mathrm{Li}_{/} \mathrm{Fe} \mathrm{S}_{2}$ and $\mathrm{Li} / \mathrm{SOCl}_{2}$ technologies. These technologies allow for long term stimulation, their minimal energy density is higher than $3.102 \mathrm{mWh} / \mathrm{g}$ (corresponding in our case to approximately 48 hours of stimulation per gram), and 


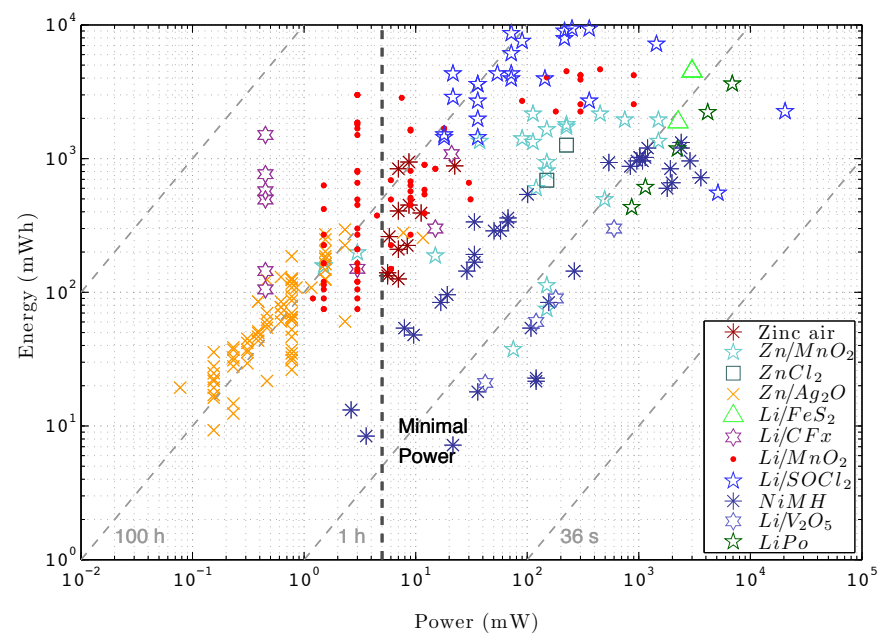

(a)

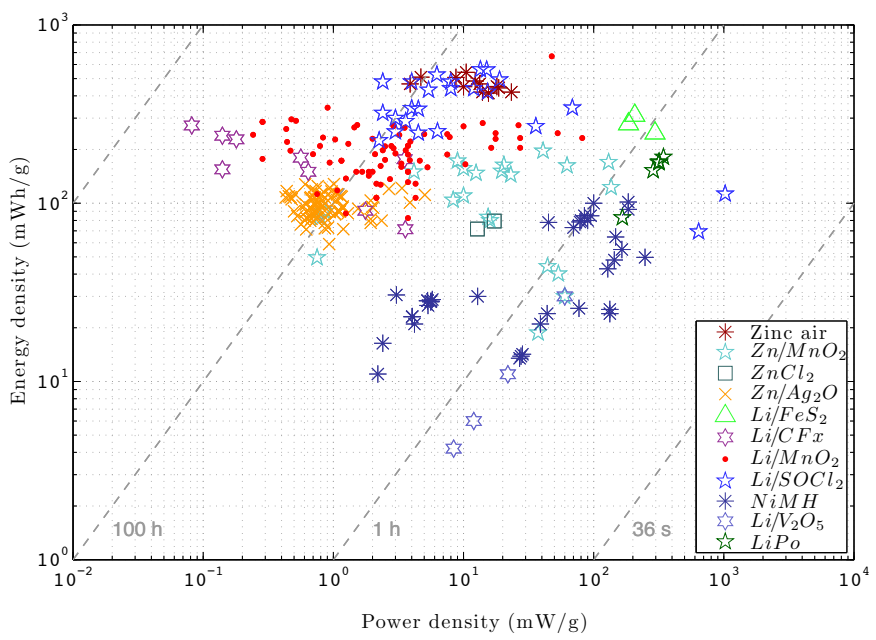

(b)

Fig. 5. Evaluation of small (commercially available less than $20 \mathrm{~g}$ ) batteries technologies: Zinc/Air, Zinc/Manganese dioxide $\left(\mathrm{Zn} / \mathrm{MnO} \mathrm{O}_{2}\right.$ ), Zinc cloride $\left(\mathrm{ZnCl} \mathrm{Cl}_{2}\right)$, Zinc/Silver oxide $\left(\mathrm{Zn} / \mathrm{Ag}_{2} \mathrm{O}\right)$, Lithium/Iron disulfide $\left(\mathrm{Li} / \mathrm{Fe} \mathrm{S}_{2}\right)$, Lithium/Polycorbon Monofluoride $(\mathrm{Li} / \mathrm{CF})$, Lithium/Manganese dioxide $\left(\mathrm{Li} / \mathrm{MnO}_{2}\right)$, Lithium/thyonil chloride $\left(\mathrm{Li}_{\mathrm{SOCl}}\right)$, Nickel Metal Hydrure $(\mathrm{NiMH})$, Lithium/Vanadium pentoxide $\left(\mathrm{Li} / \mathrm{V}_{2} \mathrm{O}_{5}\right)$, Lithium polymer $(\mathrm{LiPo})$; (a) energy versus power (b) energy versus power density

have satisfying specific power. Only few models of small $L i / F e S_{2}$ are available, which are not adapted for our specific spacial design needed for skull implantation.

We conduced tests with both $\mathrm{Zinc} / \mathrm{Air}$ and $\mathrm{Li} / \mathrm{SOCl}_{2}$ batteries. Nominal voltages are $3.6 \mathrm{~V}$ for $\mathrm{Li} / \mathrm{SOCl}_{2}$ and $1.35 \mathrm{~V}$ for Zinc/Air cells (1.6V in open circuit), so that three Zinc/Air cells in series are mandatory. Zinc/Air cells packaging (button package) makes them more suitable for the final version of the stimulator. We used PowerOne zinclair p675 Implant plus batteries for both tests and animal implantation.

We now focus on the requirement for peak power supply. To prevent from unexpected reset of digital parts, a decoupling capacitor was used as a secondary source to supply the current peak observed in Fig. 4(c). Ceramic capacitors are simple and good candidates for such a task as their power density is much larger than conventional batteries, even if their energy density is reduced. Using a triangle approximation of the observed peak current, the minimal decoupling capacitance providing less than $100 \mathrm{mV}$ voltage drop for the supply profile can be determined by:

$$
\begin{aligned}
C_{\text {decoupling }} & \geq \frac{Q}{\Delta V_{\min }} \\
& \approx \frac{\left(I_{\max }-I_{\text {average }}\right) \Delta t}{2 \Delta V_{\min }}=16 \mu \mathrm{F}
\end{aligned}
$$

Ceramic capacitors with these values can be found in package as small as 0603 (1608 Metric), so that impact on the final design size is negligible.

\section{IMPLANTATION ON RODENT SKULL AND EXPERIMENTAL RESULTS}

\section{A. Mechanical implantation}

All components from schematics presented in Fig. 3, except electrodes and associated blocking capacitor, have been integrated on a 6 layers printed circuit board (length: $30 \mathrm{~mm}$, height: $14 \mathrm{~mm}$ ) as presented in Fig. 6(c). As for external control, a reset switch serves the purpose of stopping the stimulation immediately and a three-wire RS-232 access for stimulation programming were used. MCU flashing can be performed via a dedicated on-board connector, allowing for stimulation program and user interface release without hardware replacement.

The circuit, batteries and electrodes were fixed on the skull using custom plastic packaging, designed using a 3D printer. The package is divided in two main parts:

- The electrode container: (Fig. 6(a)) this part, attached on the rodent's skull by surgery and fixed with dental cement, supports the electrodes for both left and right cerebral hemispheres, the blocking capacitor and an external connector (Fig. 6(b)). The plastic shape was designed as small as possible in order to limit the impact on animal behavior after surgery and acts as mechanical support for the second part's mounting

- The stimulator container: this part(Fig. 6(d)) is designed to fix the stimulation board and batteries on the skull. The top of the box includes a drilled column for the system to be screwed to the electrode container and to turn on the global system by contacting both poles of the electrical supply.

We fabricated the plastics shape with a Makerbot Replicator 2 with natural PLA (polylactic acid polymer) material. The height of the global system when mounted on the animal is $24 \mathrm{~mm}$. The use of a two parts system allows for device retrieval, and facilitates MRI or other analysis when needed. It also allows stimulator re-use when the rodent is sacrificed.

A custom electrode system has been developed. This system permits a two side implantation in one surgery. The distance between the two electrodes is set according to the rat brain atlas of Paxinos and Watson (1986) and correspond to the distance between the two targeted STN. The electrodes support 


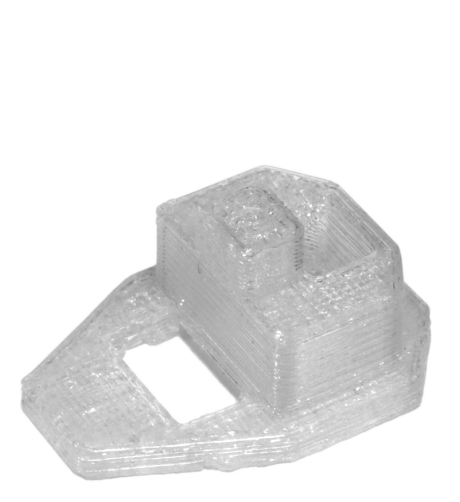

(a)

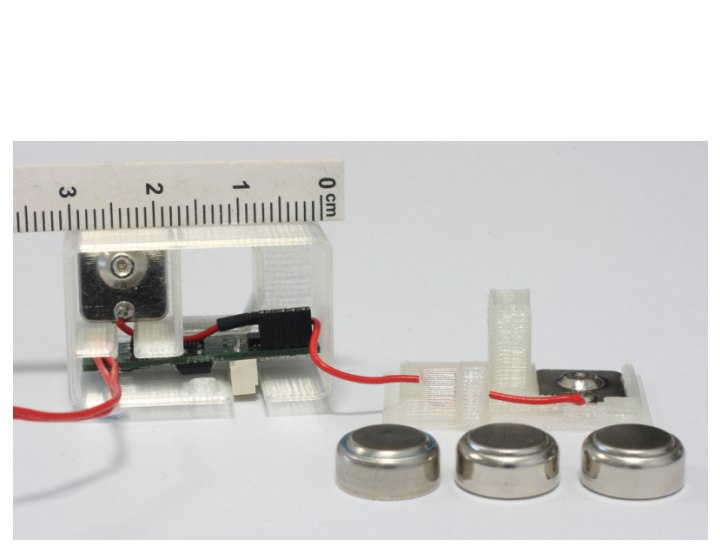

(d)

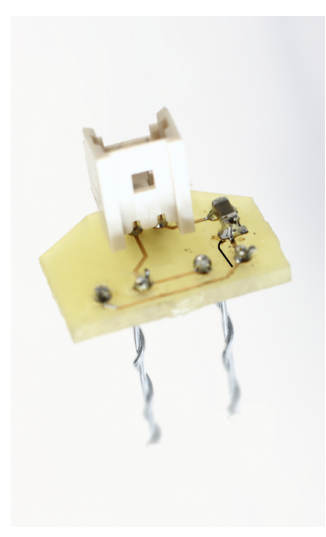

(b)

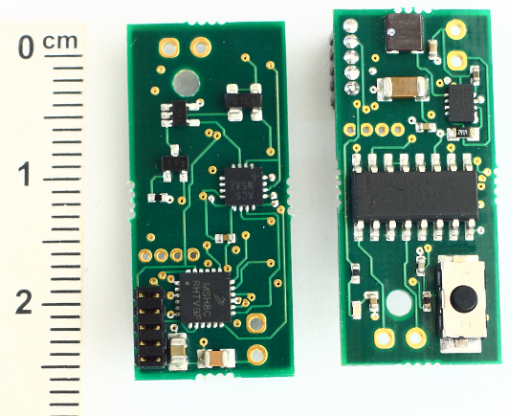

(c)

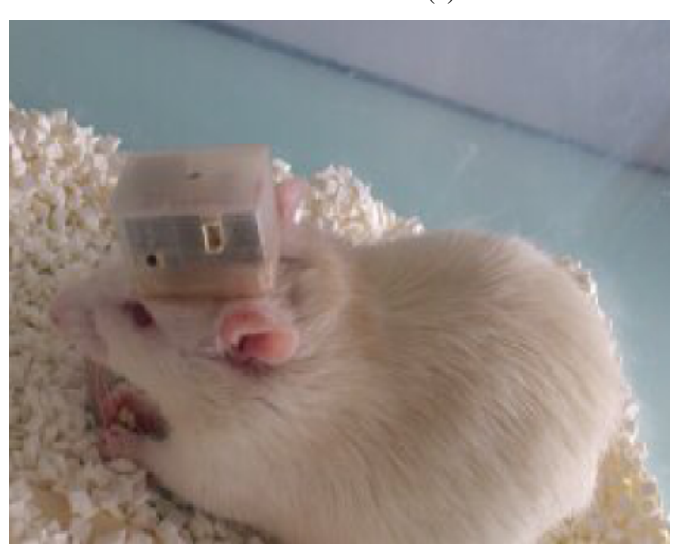

(e)

Fig. 6. Stimulator, circuit packaging and implantation on rodents' skull. (a) electrode container; this part is fixed with cement on the cranium of the rodent (b) custom electrodes for bilateral STN stimulation; both electrodes are in parallel and the support board includes the blocking capacitor (c) electrical stimulator board (d) assembled stimulator in container, shown with used Zinc/Air batteries, the top is then screwed on the electrode container after the surgery (e) stimulator chronically implanted on a rat; a three wire cable is connected to the device only for waveform programming, stimulation remains active during all experimentation phases.

board is shown in Fig. 6(b). A high value high voltage capacitor $(10 \mu \mathrm{F}$ under $25 \mathrm{~V}$ MURATA 0603[1608Metric]) is embedded as close as possible to the electrodes to provide DC current blocking in any case and lessen the impact of passive components surface on stimulator main board.

The developed electrodes are needle-like two wire electrodes of twisted tungsten (built from tungsten Wire 008 Bare, .0110 Coated, Phymep, France). Electrode diameter has been chosen to be similar with a widely used electrode for monolateral electrical stimulation of STN structures on rodents [58]. A first pole is made by a wire section. For the second pole, the current return half-cell electrode was constructed by a $2 \mathrm{~mm}$ long wrap of the second conductor. The distance between the two poles is $1 \mathrm{~mm}$. Electrodes are associated in parallel (both cathods are connected together, both current-return paths are connected together), and connected in series with the blocking capacitor.

The overall stimulator has a weight of $13.8 \mathrm{~g}$, under the limit of $20 \mathrm{~g}$ for the targeted rodent.

\section{B. Surgery and experimental results}

The stimulator was implanted and tested on an adult male Sprague-Dawley rat weighing $324 \mathrm{~g}$. Surgical and experimental procedures were performed in accordance with European Communities Council Directive 2010/63/UE and National Institute of Health Guide for Care and Use of Laboratory Animals.

A first anaesthesia was induced using a mixture of Xylazine $(10 \mathrm{mg} / \mathrm{kg})$ and Ketamine $(7.5 \mathrm{mg} / \mathrm{kg})$. Custom concentric bipolar electrodes for both cerebral hemispheres were then implanted simultaneously in the STN under stereotaxic conditions according to the atlas of Paxinos and Watson (1986).

After this first implantation, the stimulation hardware was not directly screwed on the skull to limit postsurgical risks. Smoothed angles in the electrode support enhance the healing and thus limit animal awareness of additional material on the top of the head. We observed no skin reaction, infection or rejection phenomena against the PLA electrode container. The stimulator container was fixed on the animal eight days after the implantation of the stimulating electrodes, during a short and light anaesthesia induced using isoflurane (5\% during 1 to $2 \mathrm{~min}$ ) to prevent the rat sudden movement during the 
placement.

Electrical parameters of chronic stimulation were chosen according to those used in the stimulated Parkinsonian patient showing reversal of motor deficits. The frequency was fixed to $130 \mathrm{~Hz}$ and pulse width to $60 \mu \mathrm{s}$. The stimulation intensity was gradually increased (by steps of $50 \mu \mathrm{A}$ ) in order to determine the required level. Based on these tests, we used an intensity of $400 \mu \mathrm{A}$ per side, which was just below the threshold $(450 \mu A)$ inducing the manifestation of abnormal involuntary movements. The rat was then chronically stimulated for 3 weeks during which the animal presented normal behaviour without any visible discomfort.

\section{DISCUSSION AND CONCLUSION}

Our objective was to develop a stimulator that allows safe chronic bilateral DBS in freely moving small rodents and reproduces the human therapeutic conditions. In section II, we exposed constraints that such devices have to satisfy during experiments on animal populations: tissue safety, bilateral stimulation, programmability, adaptation to freely moving animal, stimulation life time and reusability in a context of low cost devices. The design choices we made respect these specifications and our system was both electrically and in vivo characterized.

We discussed the performances of our stimulator in comparison with state-of-the-art systems for rodents, referenced in section II-B. In [24], the stimulator was only tested in saline solution and authors of [16] and [26] give no detailed information about in vivo experiments, so we examined only [25], [27] and [28] which results are shown in Table II. A first part sums up characteristics related to in vivo experimentation, whereas a second part synthesizes important electrical features. We note that none of these in vivo used devices are based on ASIC solution. Stimulators are presented in a chronological order. Most recent devices are fixed on the skull, which certainly provides greater ease of handling and reduces the risk of infection. Nevertheless the implantable device presented in [25] has electrical features compatible with required properties for DBS, in terms of current range and maximal voltage. In [27], stimulation is in voltage mode, and limited to small values that could be problematic when considering focal electrode with higher impedances. This is not compatible with our specification for current mode, ensuring a better control of injected charge. In [28], stimulation is in current mode but long term tissue safety is compromised by the absence of biphasic charge balancing.

The limited performance of our system in term of lifetime stimulation can be explained by the hardware capacity to generate a more complex waveform than in [28]. The digital part in our system is faster than [25,27], thus can reach better timing precision and accurate charge balancing. Moreover, the development of a two-piece mechanical packaging as in [28] allows for changing batteries without any additional surgery, so that the life time of the stimulation on one animal can be easily increased. Electrical stimulators in the litterature are often realized with ASICs, nevertheless all of chronic in vivo demonstrated devices use discrete components. This consideration can be explained by the need of cost-effectiveness,
TABLE III

STIMULATORS FOR RODENT COMPARISON

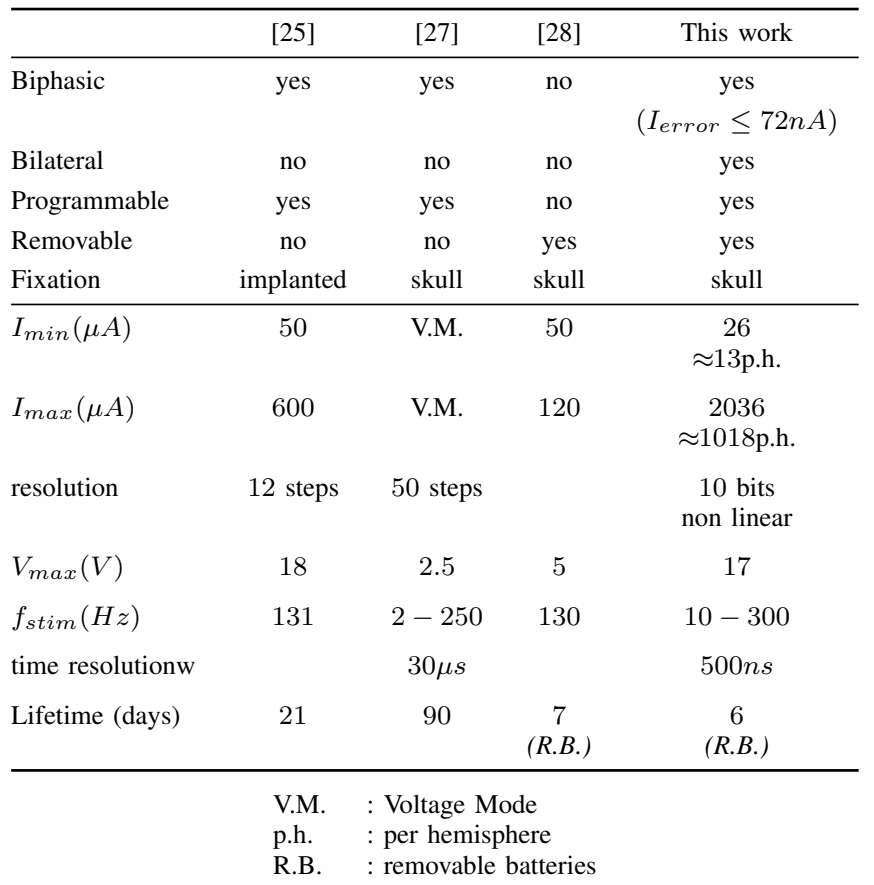

related to long-term experimentation on animal populations. Finally, let us note that no figure of merit dedicated to in vivo electrical stimulation exists yet, which could quantify differences between existing alternatives, and help select optimal solutions for a given experimentation.

To summarize, we developed in this paper the design procedure of an embedded stimulator, from the front-end circuit, to the choice of battery and packaging. We detailed the qualitative specifications on such systems for experimentation on small animals and deduced descriptive and quantitative elements, so that this reasoning can be re-used for further development of new devices for chronic implanted stimulation.

\section{ACKNOWLEDGMENT}

Research was supported by the french Agence Nationale de la Recherche, projects 'STN Oscillation' ANR-08-MNPS-036 and 'HYRENE' 2010-Blan-031601. The authors also want to thank Philippe Caiis and Zahroudin Salim for their help on prototype realization, and Damien Blanchard for the guidance in mechanical conception.

\section{REFERENCES}

[1] A. L. Benabid, P. Pollak, C. Gervason, D. Hoffmann, D. M. Gao, M. Hommel, J. E. Perret, and J. de Rougemont, "Long-term suppression of tremor by chronic stimulation of the ventral intermediate thalamic nucleus." Lancet, vol. 337, no. 8738, pp. 403-6, Mar. 1991.

[2] P. Limousin, P. Pollak, A. Benazzouz, D. Hoffmann, J. F. Le Bas, E. Broussolle, J. E. Perret, and A. L. Benabid, "Effect of parkinsonian signs and symptoms of bilateral subthalamic nucleus stimulation." Lancet, vol. 345, no. 8942, pp. 91-5, Jan. 1995.

[3] P. Limousin, P. Krack, P. Pollak, A. Benazzouz, C. Ardouin, D. Hoffmann, and A. L. Benabid, "Electrical stimulation of the subthalamic nucleus in advanced Parkinson's disease." N. Engl. J. Med., vol. 339, no. 16 , pp. $1105-11$, Oct. 1998. 
[4] K. L. Collins, E. M. Lehmann, and P. G. Patil, "Deep brain stimulation for movement disorders.” Neurobiol. Dis., vol. 38, no. 3, pp. 338-45, Jun. 2010

[5] A. Benazzouz, C. Gross, J. Féger, T. Boraud, and B. Bioulac, "Reversal of Rigidity and Improvement in Motor Performance by Subthalamic High-frequency Stimulation in MPTP-treated Monkeys," Eur. J. Neurosci., vol. 5, no. 4, pp. 382-389, Apr. 1993.

[6] A. L. Benabid, "Deep brain stimulation for Parkinson's disease." Curr Opin. Neurobiol., vol. 13, no. 6, pp. 696-706, Dec. 2003.

[7] C. Hammond, R. Ammari, B. Bioulac, and L. Garcia, "Latest view on the mechanism of action of deep brain stimulation." Mov. Disord., vol. 23 no. 15, pp. 2111-21, Nov. 2008.

[8] R. J. Coffey, "Deep brain stimulation devices: a brief technical history and review." Artif. Organs, vol. 33, no. 3, pp. 208-20, Mar. 2009

[9] D. R. Merrill, M. Bikson, and J. G. R. Jefferys, "Electrical stimulation of excitable tissue: design of efficacious and safe protocols." J. Neurosci. Methods, vol. 141, no. 2, pp. 171-98, Feb. 2005.

[10] W. Meissner, C. E. Gross, D. Harnack, B. Bioulac, and A. Benazzouz, "Deep brain stimulation for Parkinson's disease: potential risk of tissue damage associated with external stimulation." Ann. Neurol., vol. 55, no. 3, pp. 449-50, Mar. 2004.

[11] J. Volkmann, E. Moro, and R. Pahwa, "Basic algorithms for the programming of deep brain stimulation in Parkinson's disease." Mov Disord., vol. 21 Suppl 1, pp. S284-9, Jun. 2006.

[12] J. Holsheimer, E. A. Dijkstra, H. Demeulemeester, and B. Nuttin, "Chronaxie calculated from current-duration and voltage-duration data.' J. Neurosci. Methods, vol. 97, no. 1, pp. 45-50, Apr. 2000.

[13] K. S. Bankiewicz, E. H. Oldfield, C. C. Chiueh, J. L. Doppman, D. M. Jacobowitz, and I. J. Kopin, "Hemiparkinsonism in monkeys after unilateral internal carotid artery infusion of 1-methyl-4-phenyl-1,2,3,6tetrahydropyridine (MPTP).” Life Sci., vol. 39, no. 1, pp. 7-16, Jul 1986.

[14] R. Heikkila, A. Hess, and R. Duvoisin, "Dopaminergic neurotoxicity of 1-methyl-4-phenyl-1,2,5,6-tetrahydropyridine in mice," Science (80-. )., vol. 224, no. 4656, pp. 1451-1453, Jun. 1984

[15] U. Ungerstedt, "6-Hydroxy-dopamine induced degeneration of central monoamine neurons." Eur. J. Pharmacol., vol. 5, no. 1, pp. 107-10, Dec. 1968.

[16] K. Nowak, E. Mix, J. Gimsa, U. Strauss, K. K. Sriperumbudur, R. Benecke, and U. Gimsa, "Optimizing a rodent model of Parkinson's disease for exploring the effects and mechanisms of deep brain stimulation." Parkinsons. Dis., vol. 2011, p. 414682, Jan. 2011.

[17] C. Delaville, J. Chetrit, K. Abdallah, S. Morin, L. Cardoit, P. De Deurwaerdere, and A. Benazzouz, "Emerging dysfunctions consequent to combined monoaminergic depletions in parkinsonism," Neurobiology of disease, vol. 45, no. 2, pp. 763-773, 2012.

[18] H. Matsumura, G. Kinoshita, S. Satoh, T. Osaka, and O. Hayaishi, "A novel apparatus that permits multiple routes for infusions and body-fluid collections in a freely-moving animal." J. Neurosci. Methods, vol. 57 no. 2, pp. 145-9, Apr. 1995

[19] A. L. Spieles-Engemann, M. M. Behbehani, T. J. Collier, S. L. Wohlgenant, K. Steece-Collier, K. Paumier, B. F. Daley, S. Gombash L. Madhavan, G. T. Mandybur, J. W. Lipton, B. T. Terpstra, and C. E. Sortwell, "Stimulation of the rat subthalamic nucleus is neuroprotective following significant nigral dopamine neuron loss." Neurobiol. Dis., vol. 39, no. 1, pp. 105-15, Jul. 2010.

[20] S. C. Dulawa, D. K. Grandy, M. J. Low, M. P. Paulus, and M. A. Geyer, "Dopamine D4 receptor-knock-out mice exhibit reduced exploration of novel stimuli." J. Neurosci., vol. 19, no. 21, pp. 9550-6, Nov. 1999.

[21] Y.-N. Wu, B. I. Hyland, and J.-J. J. Chen, "Biomechanical and electromyogram characterization of neuroleptic-induced rigidity in the rat.' Neuroscience, vol. 147, no. 1, pp. 183-96, Jun. 2007.

[22] A. P. Carobrez and L. J. Bertoglio, "Ethological and temporal analyses of anxiety-like behavior: the elevated plus-maze model 20 years on." Neurosci. Biobehav. Rev., vol. 29, no. 8, pp. 1193-205, Jan. 2005.

[23] A. Sclafani and K. Ackroff, "Reinforcement value of sucrose measured by progressive ratio operant licking in the rat." Physiol. Behav., vol. 79, no. 4-5, pp. 663-70, Sep. 2003.

[24] M. Russold and J. C. Jarvis, "Implantable stimulator featuring multiple programs, adjustable stimulation amplitude and bi-directional communication for implantation in mice." Med. Biol. Eng. Comput., vol. 45, no. 7, pp. 695-9, Jul. 2007

[25] D. Harnack, W. Meissner, R. Paulat, H. Hilgenfeld, W.-D. Müller, C. Winter, R. Morgenstern, and A. Kupsch, "Continuous high-frequency stimulation in freely moving rats: development of an implantable microstimulation system," Journal of neuroscience methods, vol. 167, no. 2 pp. 278-291, 2008
[26] J. Lee, H.-G. Rhew, D. R. Kipke, and M. P. Flynn, "A 64 Channel Programmable Closed-Loop Neurostimulator With 8 Channel Neural Amplifier and Logarithmic ADC," IEEE J. Solid-State Circuits, vol. 45, no. 9, pp. 1935-1945, Sep. 2010

[27] X. Qian, H. Hao, B. Ma, X. Wen, and L. Li, "Study on DBS device for small animals." Conf. Proc. IEEE Eng. Med. Biol. Soc., vol. 2011, pp. 6773-6, Jan. 2011

[28] C. Forni, O. Mainard, C. Melon, D. Goguenheim, L. Kerkerian-Le Goff, and P. Salin, "Portable microstimulator for chronic deep brain stimulation in freely moving rats." J. Neurosci. Methods, vol. 209, no. 1, pp. 50-7, Jul. 2012.

[29] M. Azin, D. J. Guggenmos, S. Barbay, R. J. Nudo, and P. Mohseni, “A Battery-Powered Activity-Dependent Intracortical Microstimulation IC for Brain-Machine-Brain Interface," IEEE J. Solid-State Circuits, vol. 46, no. 4, pp. 731-745, Apr. 2011.

[30] P. J. Langlois, A. Demosthenous, I. Pachnis, and N. Donaldson, "Highpower integrated stimulator output stages with floating discharge over a wide voltage range for nerve stimulation." IEEE Trans. Biomed. Circuits Syst., vol. 4, no. 1, pp. 39-48, Mar. 2010.

[31] X. Liu, A. Demosthenous, and N. Donaldson, "A dual-mode neural stimulator capable of delivering constant current in current-mode and high stimulus charge in semi-voltage-mode," in Proc. 2010 IEEE Int. Symp. Circuits Syst. IEEE, May 2010, pp. 2075-2078.

[32] K. Abdelhalim and R. Genov, "CMOS DAC-sharing stimulator for neural recording and stimulation arrays," in 2011 IEEE Int. Symp. Circuits Syst. IEEE, May 2011, pp. 1712-1715.

[33] M. Hasanuzzaman, G. Simard, N. I. Krouchev, R. Raut, and M. Sawan, "Capacitive-data links, energy-efficient and high-voltage compliant visual intracortical microstimulation system," in 2013 IEEE Int. Symp. Circuits Syst. IEEE, May 2013, pp. 646-649.

[34] E. Noorsal, K. Sooksood, H. Xu, R. Hornig, J. Becker, and M. Ortmanns, "A Neural Stimulator Frontend With High-Voltage Compliance and Programmable Pulse Shape for Epiretinal Implants," IEEE J. Solid-State Circuits, vol. 47, no. 1, pp. 244-256, Jan. 2012.

[35] Ji-Jon Sit and R. Sarpeshkar, "A Low-Power Blocking-Capacitor-Free Charge-Balanced Electrode-Stimulator Chip With Less Than 6 nA DC Error for 1-mA Full-Scale Stimulation." IEEE Trans. Biomed. Circuits Syst., vol. 1, no. 3, pp. 172-83, Sep. 2007.

[36] F. Soulier, J.-B. Lerat, L. Gouyet, S. Bernard, and G. Cathébras, "A Neural Stimulator Output Stage for Dodecapolar Electrodes," in 2008 IEEE Comput. Soc. Annu. Symp. VLSI. IEEE, 2008, pp. 487-490.

[37] T. Tokuda, K. Hiyama, S. Sawamura, K. Sasagawa, Y. Terasawa K. Nishida, Y. Kitaguch, T. Fujikado, Y. Tano, and J. Ohta, "CMOSBased Multichip Networked Flexible Retinal Stimulator Designed for Image-Based Retinal Prosthesis," IEEE Trans. Electron Devices, vol. 56, no. 11, pp. 2577-2585, Nov. 2009.

[38] J. Tan, X. Liu, K. H. Wee, S.-C. Yen, Y. P. Xu, and T. C. Tan, "A monolithic programmable nerve/muscle stimulator," in Neural Engineering (NER), 2011 5th International IEEE/EMBS Conference on, April 2011, pp. 511-514.

[39] E. K. Lee and A. Lam, "A Matching Technique for Biphasic Stimulation Pulse," in 2007 IEEE Int. Symp. Circuits Syst. IEEE, May 2007, pp. $817-820$.

[40] S.-J. Chang, W.-Y. Chung, and C.-C. Chuang, "System Design of Implantable Micro-stimulator for Medical Treatments," in APCCAS 2006 - 2006 IEEE Asia Pacific Conf. Circuits Syst. IEEE, Dec. 2006, pp. $478-481$.

[41] T. G. Constandinou, J. Georgiou, and C. Toumazou, "A partial-currentsteering biphasic stimulation driver for neural prostheses," in 2008 IEEE Int. Symp. Circuits Syst. IEEE, May 2008, pp. 2506-2509.

[42] C.-S. A. Gong, M.-T. Shiue, C.-H. Su, and Y. Chang, "An Efficient Micro-Stimulator Array Using Unitary-Size DAC With Adiabatic Baseband Scheme," in 2006 13th IEEE Int. Conf. Electron. Circuits Syst. IEEE, Dec. 2006, pp. 29-32.

[43] Dai Jiang, A. Demosthenous, T. Perkins, Xiao Liu, and N. Donaldson, "A Stimulator ASIC Featuring Versatile Management for Vestibular Prostheses." IEEE Trans. Biomed. Circuits Syst., vol. 5, no. 2, pp. 14759, Apr. 2011.

[44] W. Ngamkham, M. N. van Dongen, and W. A. Serdijn, "Biphasic stimulator circuit for a wide range of electrode-tissue impedance dedicated to cochlear implants," in 2012 IEEE Int. Symp. Circuits Syst. IEEE, May 2012, pp. 1083-1086.

[45] C. Sawigun, W. Ngamkham, M. van Dongen, and A. S. Wouter "A least-voltage drop high output resistance current source for neural stimulation," in 2010 Biomed. Circuits Syst. Conf. IEEE, Nov. 2010, pp. 110-113. 
[46] D.-L. Shen and Y.-J. Chu, "A linearized current stimulator for deep brain stimulation.” Conf. Proc. IEEE Eng. Med. Biol. Soc., vol. 2010, pp. 6485-8, Jan. 2010.

[47] R. Shulyzki, K. Abdelhalim, and R. Genov, "CMOS current-copying neural stimulator with OTA-sharing," in Proc. 2010 IEEE Int. Symp. Circuits Syst. IEEE, May 2010, pp. 1232-1235.

[48] M. Willand, J. Lopez, H. de Bruin, M. Fahnestock, M. Holmes, and J. Bain, "A new system and paradigm for chronic stimulation of denervated rat muscle." J Med Biol Eng., vol. 31, no. 2, pp. 87-92, 2011.

[49] A. Eftekhar, T. Constandinou, I. Triantis, C. Toumazou, and E. Drakakis, "Towards a reconfigurable sense-and-stimulate neural interface generating biphasic interleaved stimulus," in Neural Engineering, 2007. CNE '07. 3rd International IEEE/EMBS Conference on, May 2007, pp. 438441.

[50] R. Bhandari, S. Negi, and F. Solzbacher, "Wafer-scale fabrication of penetrating neural microelectrode arrays." Biomed. Microdevices, vol. 12, no. 5, pp. 797-807, Oct. 2010.

[51] F. Kolbl, J. Sabatier, G. N'Kaoua, F. Naudet, E. Faggiani, A. Benazzouz, S. Renaud, and N. Lewis, "Characterization of a non linear fractional model of electrode-tissue impedance for neuronal stimulation," in 2013 IEEE Biomed. Circuits Syst. Conf. IEEE, Oct. 2013, pp. 338-341.

[52] S. F. Lempka, S. Miocinovic, M. D. Johnson, J. L. Vitek, and C. C. McIntyre, "In vivo impedance spectroscopy of deep brain stimulation electrodes." J. Neural Eng., vol. 6, no. 4, p. 046001, Aug. 2009.

[53] R. Latham, "Biomedical applications of batteries," Solid State Ionics, vol. 172, no. 1-4, pp. 7-11, Aug. 2004.

[54] C. L. Schmidt and P. M. Skarstad, "The future of lithium and lithium-ion batteries in implantable medical devices," J. Power Sources, vol. 97-98, pp. 742-746, Jul. 2001

[55] D. C. Bock, A. C. Marschilok, K. J. Takeuchi, and E. S. Takeuchi, "Batteries used to Power Implantable Biomedical Devices." Electrochim. Acta, vol. 84, pp. 155-164, Dec. 2012.

[56] X. Wei and J. Liu, "Power sources and electrical recharging strategies for implantable medical devices," Front. Energy Power Eng. China, vol. 2 no. 1, pp. 1-13, Mar. 2008

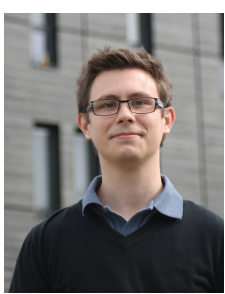

Florian Kölbl received the M.Sc. degree in electronics from ENSEIRB-Matmeca, Bor- deaux, France, in 2010 and a M.Sc degree in electrical engineering teaching from ENS Cachan, France, in 2011. He obtained the Agrgation de Gnie Electrique in 2011 He integrated in 2011 the Bioelectronic group of the IMS Laboratoy to prepare a PhD diploma at the University of Bordeaux. He is currently Teaching and Research Assistant at the University of Bordeaux.

His research is focused on circuits interacting with living tissues and, specially, the design of circuits and systems for electrical stimulation in different pathological contexts.

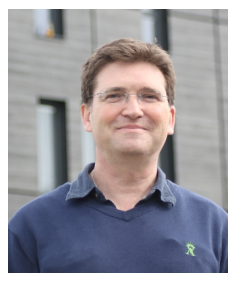

Gilles N'Kaoua joined the CNRS in 1984 and obtained the Electronic Engineer Diploma from the Conservatoire National des Arts et Metiers in 1992. In 1993, he joined the IMS Laboratory as the head of the clean room platform, to work on thin layers microsystems design. He works currently with the Bioelectronic group of IMS, as a research engineer on instrumentation and system design for in vitro or in vivo experiments. He also is in charge of the CNRS Electronics Network organization since 2001.

Frédéric Naudet is an Assistant engineer employed by the National Center for Scientific Research (CNRS) working in Bordeaux University. After completing a Professional Master degree in Bordeaux, he was appointed to CNRS position as a permanent position assistant engineer in the Neurobiology of Adaptive Processes unit at the Pierre et Marie Curie University in Paris in 2009. In 2011, he integrated the team "Monoamines, Deep Brain Stimulation \& Parkinsons disease" manage by the $\mathrm{Dr}$ Abdelhamid Benazzouz in the Institute of Neurodegenerative diseases in Bordeaux University. He works as a trainer and technical support for students for all the techniques used in the laboratory as Parkinson model surgery, extracellular electrophysiology, motor and non-motor behavior, histology, biochemical techniques. He also works in the design and development of new techniques and approaches in collaboration with other research teams and companies under the supervision of Dr Abdelhamid Benazzouz.

Florent Berthier received his Master of Science in electronics engineering from ENSEIRB-MATMECA engineering school in Bordeaux, France in 2013. $\mathrm{He}$ is currently working towards his PhD degree at the CEA of Grenoble, France.

Emilie Faggiani is finishing her PhD diploma in the field of Neuroscience and Pharmacology in Bordeaux University in 2014. After completing a master degree in Bordeaux, she integrated the team "Monoamines, Deep Brain Stimulation \& Parkinson's disease" under the supervision of Dr Abdelhamid Benazzouz. During her $\mathrm{PhD}$, she studied the impact of the monoaminergic systems on the physiopathology and therapy of Parkinsons disease. Indeed, she provided evidence of the involvement of the three monoaminergic system (dopamine, norepinephrine and serotonin) cell degeneration in the pathophysiology of motor and non motor symptoms of Parkinsons disease. Furthermore, she showed the deleterious effect of the combined monoamine depletions on the efficacy of the antiparkinsonian treatments: the Levodopa and deep brain stimulation of the subthalamic nucleus. 


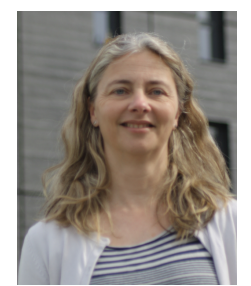

Sylvie Renaud (M07) received the M.Sc. degree in electronic engineering from Supelec, Paris, France, in 1986, and the Ph.D. degree in physics and the HDR (Research Habilitation) degree from the University of Bordeaux, Talence, France, in 1990 and 2001, respectively.

After working as a Post-Doctoral Researcher with Brandeis University, Waltham, MA, from 1991 to 1992, she was appointed as an Assistant Professor and then a Professor with ENSEIRB-MATMECA in Bordeaux Institut National Polytechnique, France, where she was successively Director of Studies and Director of Research. In 1994, she created the Engineering of Neuromorphic Systems Group in the IMS Laboratory of CNRS/University of Bordeaux where she now heads the BioElectronics Group with 12 permanent researchers. She has authored and co-authored more than 50 reviewed international articles nand communications. Her current research interests include analog and mixed neuromorphic very large scale integration (VLSI), real-time hardware simulation platforms of spiking neural networks, hybrid systems interfacing living and artificial neurons, analog application-specific integrated circuits for biological signal conditioning and events detection, active VLSI implants for neurodegenerative diseases and diabetes, and closed-loop living-artificial systems.

Dr. Renaud is an Expert for the EU Commission on FET and ICT calls, and for NSF-NIH on CRCNS calls. She has been a reviewer for IEEE journals and conferences since 1997, and organizes special sessions, tutorials, and workshops in IEEE conferences on a regular basis.

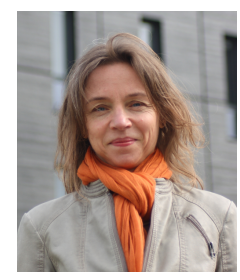

Noëlle Lewis received the $\mathrm{Ph} . \mathrm{D}$ degree in electrical engineering from the University of Bordeaux in 1997. She was appointed as and Assitant Professor with the IMS laboratory at Bordeaux University in 2000, where she carried out researches in Analog and Mixed circuits design, behavioural modeling and design automation. In 2005, she joined the research team in Engineering of Neuromorphic Systems, to contribute to solve some critical points related to analog integration with IP reuse techniques. In 2010 she was the head of a new research team focusing on electronics interfacing biology, ELIBIO, in which 3 permanent researchers, 2 engineers and 3 Ph.D students are involved and has been a full Professor in 2013 .

Her main research interests are front-end circuits for biomedical applications, including bio-signal acquisition and electrical stimulation ; the biophysical interraction and its characterisation at the tissue-electrode interface ; real-time and low power processing for closed-loop neural stimulation. The ELIBIO team is involved in several interdisciplinary projects funded by national or international agencies and aiming therapeutic innovations in the case of Deep Brain Stimulation, spinal cord lesion or diabetes.

Abdelhamid Benazzouz is a Neurophysiologist Researcher employed by the INSERM Institute working in Bordeaux University. After completing a Master degree in Morocco, he went to Bordeaux to prepare his $\mathrm{PhD}$ diploma in the field of Neuroscience and Pharmacology that he obtained in 1993. During his $\mathrm{PhD}$, he was the first to develop high frequency stimulation (HFS) of the subthalamic nucleus (STN) as a therapeutical approach of Parkinsons disease. After the demonstration in the non-human primate model of the disease that HFS of the STN improved all the cardinal motor symptoms, he joined as a Research Fellow the Inserm unit of Professor Alim-Louis Benabid in Grenoble to participate in transfering this approach to patients.

In parallel with his hospital activity as a Neurophysiologist performing the electrophysiological mapping during surgery, he was the head of a research group in the Inserm unit investigating the functional mechanisms of this approach in animal models. In 1998 he was appointed to Inserm position as a permanent position researcher. In 2001, he came back to Bordeaux as a PI in the CNRS unit of Professor Bernard Bioulac. In 2005 he was promoted to Research Director position. Since 2011, he is the leader of the Team "Monoamines, Deep Brain Stimulation \& Parkinsons disease" in the Institute of Neurodegenerative diseases in Bordeaux University.

He has published more than 100 papers in peer-reviewed journals. Abdelhamid Benazzouz obtained the National Academy of Medicine award in 2003 and the Academy of Science award in 2007. 